\title{
Fundamentação das decisões judiciais, consequencialismo e pandemia
}

\author{
Grounds for judicial decisions, consequentialism and pandemics \\ Fundamento de las decisiones judiciales, consecuencialismo y pandemia
}

Recebido: 14/07/2021 | Revisado: 21/07/2021 | Aceito: 26/07/2021 | Publicado: 02/08/2021

\author{
Natan Galves Santana \\ ORCID: https://orcid.org/0000-0001-6248-8070 \\ Universidade Paranaense, Brasil \\ E-mail: ngalvess@gmail.com \\ Letícia Bianca Pinheiro \\ ORCID: https://orcid.org/0000-0002-7227-9894 \\ Universidade Paranaense, Brasil \\ E-mail: leticiabiancap@hotmail.com \\ José Miguel Garcia Medina \\ ORCID: https://orcid.org/0000-0002-3669-5145 \\ Universidade Paranaense, Brasil \\ E-mail: medina@medina.adv.br
}

\begin{abstract}
Resumo
O presente estudo busca abordar o dever de fundamentação nas decisões judiciais em seu sentido amplo (motivação e justificação), como acesso ao Estado de Democrático de Direito e a segurança jurídica, bem como abordar o consequencialismo, como vem sendo tratado no direito brasileiro e os perigos das fundamentações baseadas em argumentos morais. Destaca-se que toda fundamentação deverá analisar o viés social e como a decisão afetará a sociedade como todo. Para isso, elencará quais os objetivos desses institutos no direito processual sob a ótica de uma sociedade contemporânea e em constante mudança. Ressalta-se que com a pandemia do Covid-19 que assola o país, tal temática ganhou mais espaço, considerando que houve aumento nas decisões baseadas em argumentos morais que visam decidir em favor do bem-estar coletivo. Portanto, elenca quais os resultados negativos e positivos uma decisão consequencialista implica para a sociedade. O presente trabalho optou-se pela metodologia dedutiva, com pesquisas bibliográficas em doutrinas, legislação infraconstitucional e constitucional, além de analisar as decisões dos Tribunais.

Palavras-chave: Consequencialismo; Fundamentação judicial; Motivação.
\end{abstract}

\begin{abstract}
This study seeks to address the duty of reasoning in court decisions in its broad sense (motivation and justification), such as access to the Democratic Rule of Law and legal security, as well as addressing consequentialism, as it has been treated in Brazilian law and the dangers of reasons based on moral arguments. It is noteworthy that every reasoning should analyse the social bias and how the decision will affect society as a whole. For this, it will list the objectives of these institutes in procedural law from the perspective of a contemporary and constantly changing society. It is noteworthy that with the Covid-19 pandemic that devastates the country, this issue has gained more space, considering that there was an increase in decisions based on moral arguments that aim to decide in favor of collective well-being. Therefore, it lists which negative and positive results a consequentialist decision has implications for society. The present work, the deductive methodology was chosen, with bibliographical research on doctrines, infra-constitutional and constitutional legislation, in addition to analysing the decisions of the Courts.
\end{abstract}

Keywords: Consequentialism; Judicial reasoning; Motivation.

\section{Resumen}

Este estudio busca abordar el deber de razonamiento en las decisiones judiciales en su sentido amplio (motivación y justificación), como el acceso al Estado de Derecho Democrático y la seguridad jurídica, así como abordar el consecuencialismo, tal como ha sido tratado en la legislación brasileña y los peligros de las razones basadas en argumentos morales. Es de destacar que todo razonamiento debe analizar el sesgo social y cómo la decisión afectará a la sociedad en su conjunto. Para ello, enumerará los objetivos de estos institutos en derecho procesal desde la perspectiva de una sociedad contemporánea y en constante cambio. Es de destacar que con la pandemia Covid-19 que arrasa el país, este tema ha ganado más espacio, considerando que hubo un aumento de decisiones basadas en argumentos morales que apuntan a decidir a favor del bienestar colectivo. Por lo tanto, enumera los resultados negativos y positivos que una decisión consecuencialista tiene implicaciones para la sociedad. El presente trabajo se optó por la metodología deductiva, con investigación bibliográfica sobre doctrinas, legislación infraconstitucional y constitucional, además de analizar las decisiones de los Tribunales.

Palabras clave: Consecuencialismo; Motivación; Razonamiento judicial. 


\section{Introdução}

O Estado Constitucional de Direito assegura diversas garantias aos cidadãos. Dentre elas, destaca-se a fundamentação das decisões judiciais, considerada de suma importância para garantir a segurança jurídica e o Estado de Direito.

Neste cenário, busca-se analisar o dever de fundamentação em seus aspectos gerais, bem como o tratamento da temática no Código de Processo Civil de 2015, tendo em vista que esse Código trouxe várias mudanças, em relação ao anterior.

A Lei de Introdução as Normas do Direito Brasileiro (Dec.-Lei 4.657/1942), com a reforma da Lei 13.655/2018, passou a dispor que deverá ocorrer uma análise das "consequências práticas da decisão" (art. 20), observando-se, por exemplo, como afetarão a sociedade, logo, a fundamentação estará atrelada ao consequencialismo. Assim, surge o perigo do uso dos argumentos e fundamentações de cunho moral, político e religioso, na tomada de decisões judiciais.

Percebe-se a importância, à luz do referido texto legal, do consequencialismo na fundamentação da decisão judicial, ou, sob certo ponto de vista, a linha tênue entre fundamentação e consequencialismo. Já que "não se decidirá com base em valores jurídicos abstratos sem que sejam consideradas as consequências práticas da decisão" (art. 20, caput, da Lei 13.655/2018, na redação da Lei 13.655/2018), esta análise deverá estar presente no momento da tomada da decisão. Desse contexto normativo surgem alguns questionamentos, como: Qual o motivo da fundamentação? O ato de fundamentar protege as partes e ou a democracia? O que não pode ser considerado fundamentação? Quais as inovações decorrentes do CPC de 2015? O que ocorrerá com a ausência de fundamentação? Como a fundamentação se liga ao consequencialismo? O consequencialismo é benéfico ou prejudicial? Quais "consequencialismos” podem ser identificados no Brasil?

O consequencialismo ganha força quando se está diante de problemas novos, sem uma solução aparente, como nos casos das decisões judiciais referentes à pandemia do coronavírus, em que tem havido judicialização de assuntos políticos, o que abre espaço para a aplicação do consequencialismo. Desse modo, o presente trabalho tem por objetivo analisar as decisões consequencialistas e seus impactos na sociedade e no direito.

\section{Metodologia}

Para o presente trabalho optou-se pela metodologia dedutiva no qual utiliza argumentos gerais e aceitos para se chegar a uma conclusão que também será aceita, tal método é utilizado, principalmente, por pesquisadores que buscam um raciocínio efetivamente lógico (Mezzaroba; Monteiro, 2009).

De acordo com Mezzaroba e Monteiro (2009, p. 65) “a questão fundamental da dedução está na relação lógica que deve ser estabelecida entre as proposições apresentadas, a fim de não comprometer a validade da conclusão. Aceitando as premissas como verdadeiras, as conclusões também o serão".

Por fim, a metodologia dedutiva teve suporte na pesquisa realizada em doutrinas e na legislação.

\section{Resultados e Discussão}

\subsection{Dever de fundamentação: aspectos gerais}

Preliminarmente, convém esclarecer a etimologia das palavras motivação e justificação, eis que englobam a palavra fundamentação. Assim, cita-se:

[...] motivação e justificação são palavras que têm significados diferentes, mas a fundamentação das decisões judiciais exige (ou abrange) também motivação e justificação. Motivo é expressão oriunda do latim motivu, "é o que move alguém a fazer alguma coisa"; justificar, por sua vez, de justificare, de justus e facere. Ao fundamentar, o juiz expõe o que moveu a chegar a dada conclusão (motivu), e deve, também proferir uma decisão justa (justificare) (Medina, 2020c, s. p.). 
Registra-se, ainda que a motivação das decisões judiciais é "inerente ao Estado Constitucional e constitui verdadeiro banco de prova do direito ao contraditório das partes" (Marinoni; Arenhart; Mitidiero, 2020, s. p.).

No Estado de Direito não se permite a prolação de decisões abusivas e arbitrárias. A motivação é a garantia do controle da adequação, a qual refletirá em toda atividade processual com a explanação analítica que deverá ser realizado pelo magistrado. O Estado Democrático repudia a ausência de motivação, já que o cumprimento do dever respectivo por seus destinatários é uma decorrência da realização dos direitos fundamentais (Araújo, 2016).

O dever de fundamentação por vezes é trazido pela doutrina como dever de motivação ou dever de justificação das decisões judiciais. Quando vistos dessa forma, referem-se à fundamentação em contexto geral e não isoladamente às palavras motivação e justificação, conforme acima explanado.

O dever de fundamentação também é compreendido como um direito fundamental de todo cidadão, considerando que toda decisão deverá ser justificada. Sob esse prisma, percebe-se que a fundamentação é um mecanismo que visa impedir julgamentos arbitrários. (Canotilho apud Medina, 2020b).

O dever de fundamentar a decisão judicial é elencado no art. 93, IX da Constituição Federal, e deve ser cumprido sob pena de nulidade dos atos praticados pelo magistrado. A fundamentação das decisões judiciais não interessa apenas às partes ou às instâncias superiores, mas a toda sociedade, a quem devem ser prestadas contas (accountability) sobre o modo como está sendo administrada a Justiça (Taruffo apud Medina, 2020b).

Para Rodrigo Ramina de Lucca (2019, p. 80), a natureza constitucional do dever de motivação das decisões se justifica pelas seguintes razões:

[...] (a) racionalização da atividade jurisdicional; (b) controle de juridicidade da decisão; (c) legitimação do exercício do poder jurisdicional; (d) proteção do devido processo legal e a promoção de várias de suas garantias; (e) melhora da qualidade das decisões ao forçar o efetivo exame da causa e aumentar o tempo de meditação sobre ela; (f) redução do número de recursos e $(\mathrm{g})$ promoção da segurança jurídica ao definir a interpretação dos dispositivos normativos e tornar possível a homogeneização jurisprudencial pelos Tribunais Superiores.

A fundamentação da decisão judicial também assegura a realização de outras garantias constitucionais, como ampla defesa, contraditório, inércia jurisdicional, e imparcialidade judicial (Lucca, 2019).

Segundo Araújo (2016, p. 165), a motivação precisa ser clara, com o objetivo de ser fácil a interpretação e entendimento da decisão. Esclarece o autor que a obscuridade nasce de casos difíceis de serem explicados e "[...] um dos meios não usuais de buscar esse objetivo é a fundamentação dos embargos de declaração pela obscuridade da decisão".

A motivação/fundamentação das decisões judiciais pode ser compreendida de duas formas. A primeira "[...] pode ser concebida como uma reprodução fiel do raciocínio desenvolvido pelo magistrado para decidir [...]”. A segunda forma baseia-se na concepção de que "[...] a motivação seria a representação de um raciocínio "justificativo" [...]", destacando-se que nessa segunda concepção, “[...] seriam desenvolvidos, sempre, dois tipos de raciocínio judicial: o decisório e o justificativo. O primeiro seria formado pelos verdadeiros motivos pelos quais a decisão foi tomada; e o segundo, apresentado na motivação, traria uma argumentação justificativa da decisão previamente tomada.” (Lucca, 2019, p. 81).

É possível constatar que a fundamentação também é um dever que corresponde a uma garantia àquele que busca no judiciário a solução de problemas. Observa-se que ela tem dupla função: a primeira é interna ou endoprocessual e tem ligação com o processo pois permite que as partes conheçam as razões das decisões proferidas para possível impugnação ou recurso a instância superior. Por outro lado, existe a função externa ou extraprocessual, que se liga à prestação de contas por parte do Poder Judiciário, de modo a viabilizar o controle da atividade jurisdicional estatal pela sociedade (Francesconi, 2019).

O dever de motivação/fundamentação das decisões judiciais decorre de regra jurídica constitucional e processual. A nosso ver, não se está, no caso, diante de princípio "ponderável” com outros, que lhes poderiam ser opostos. 
Independentemente da diferenciação que se pode empreender entre princípio e regra, consideramos que, no caso, está-se diante de uma regra. As regras ou são válidas ou não são e os princípios têm peso variado segundo cada caso, inclusive podendo-se afastar um princípio quando em confronto com outros princípios; quanto à regra constitucional que impõe o dever de fundamentação, qualquer outra que venha a excepcioná-la poderá ser considerada inconstitucional e, por consequência, inválida (Lucca, 2019).

O dever de fundamentação passou a ser uma "arma" contra o arbítrio do Estado, com bem elencam Streck e Raatz (2017):

À noção elementar de que o dever de fundamentação funcionava como uma espécie de ferramenta contra arbítrio judicial, foram se agregando outros elementos, como a garantia da imparcialidade do juiz, o controle da legalidade da decisão, e a possibilidade de impugnação das decisões. Há quem diga que, no bojo do Estado Democrático de Direito, a fundamentação das decisões, sem perder o caráter de freio contra eventuais arbitrariedades do julgador, passou a ser vista, também, como "elemento essencial de uma ideologia democrática da justiça".

Os autores afirmam, ainda, que o dever de fundamentação foi transformado, não mais se tratando apenas de garantia contra o abuso do Estado. Entretanto, deve seguir os ditames do constitucionalismo contemporâneo, no qual não se admite discursos morais, políticos e pragmáticos. (Streck; Raatz, 2017)

Rigorosamente, o dever de fundamentação não deveria ser enquadrado como um "ônus", mas dever: fundamentar a decisão não é escolha do magistrado, mas algo pelo qual ele é responsável.

\subsection{Fundamentação no CPC de 2015}

Em complemento à Constituição Federal, o art. 11 do Código de Processo Civil de 2015 reza que "todos os julgamentos dos órgãos do Poder Judiciário serão públicos, e fundamentadas todas as decisões, sob pena de nulidade" (Brasil, 2015).

A fundamentação deverá ser completa, logo, não poderá decorrer de uma simples menção na decisão de como o juiz chegou a determinada conclusão. A decisão deve ter ligação com as alegações produzidas pelas partes, com objetivo de deixar claras as posições jurídicas. (Mitidiero, 2019).

Segundo Medina (2020c, s. p.) a fundamentação constitui ato de inteligência, declaração e resposta. Na primeira o magistrado elencará como chegou à norma para que o problema fosse solucionado, como foram compreendidos os fatos, as alegações e as provas. Por sua vez, declaração porque desempenha a segurança do direito, pois é fundamento para construção da norma jurídica, passando ocupar papel importante, pois estrutura e organiza para construir uma decisão íntegra. Por fim, constitui resposta, já que se espera uma decisão colocando fim ao litígio, sendo necessário o diálogo ao longo do processo, logo, a decisão é a conclusão do diálogo, e que se esta resposta foi incompleta ou uma motivação fictícia, haverá violação ao dever de fundamentação, bem como ao princípio do contraditório.

Tamanha importância da fundamentação, o Código de Processo Civil de 2015, no art. 489, § $1 .^{\circ}$, considera a fundamentação como elemento essencial, inovando ao trazer casos em que se considera que a decisão não é fundamentada:

I - se limitar à indicação, à reprodução ou à paráfrase de ato normativo, sem explicar sua relação com a causa ou a questão decidida;

II - empregar conceitos jurídicos indeterminados, sem explicar o motivo concreto de sua incidência no caso;

III - invocar motivos que se prestariam a justificar qualquer outra decisão;

IV - não enfrentar todos os argumentos deduzidos no processo capazes de, em tese, infirmar a conclusão adotada pelo julgador;

V - se limitar a invocar precedente ou enunciado de súmula, sem identificar seus fundamentos determinantes nem demonstrar que o caso sob julgamento se ajusta àqueles fundamentos; 
VI - deixar de seguir enunciado de súmula, jurisprudência ou precedente invocado pela parte, sem demonstrar a existência de distinção no caso em julgamento ou a superação do entendimento (Brasil, 2015).

De acordo com o Enunciado 303 do Fórum Permanente de Processualista Civis - FPPC o rol descrito nos incisos do § $1^{\circ}$, do art. 489, CPC é meramente exemplificativo.

Nesta via, para Nery Junior e Nery (2019, s. p.) a ausência de fundamentação, nos termos do dispositivo acima mencionada, converge em duas situações: a primeira é a generalidade ou vazio do texto, enquanto a outra é falta de enfrentamento de todos argumentos.

Diante disso, é possível observar que o dispositivo supramencionado segue os ditames contemporâneo do princípio do contraditório, sob aspecto de um julgador neutro, no qual acompanha ao diálogo das partes, e ao decidir elencará a fundamentação. Assim, será considerado que participou do contraditório, bem como o juiz poderá decidir por fundamentos não mencionado pelas partes, entretanto, deve das partes oportunidade para manifestar a respeito (Alvim, 2019, s. p.).

Desta feita, se ocorrer alguma das situações mencionadas no $\S 1^{\circ}$, do art. 489 do CPC, será considerada nula a decisão. Não basta constar da decisão os fundamentos favoráveis à sua conclusão, fazendo-se necessária a análise de cada argumento que contraria a tese defendida, para assim garantir que a legitimidade do diálogo. (Alvim, 2020 s. p.).

Frisam George Salomão Leite, Lenio Luiz Streck e Nelson Nery Junior (2017, p. 354), que:

[...] o referido $\$ 1^{\circ}$, do art. 489 não criou novo dever aos julgadores, vindo apenas reforçar aquele já constante da Constituição Federal. Isso é de fundamental importância, principalmente para o que se pretende dizer no presente artigo: a explicitação contida no art. $489, \S 1^{\circ}$, do CPC/2015 não deve servir de base apenas para decisões judiciais que tenham conteúdo jurisdicional, prestando-se também a verificar se as decisões administrativas dos tribunais mostramse, ou não, fundamentadas. Não se está a dizer peremptoriamente que o referido dispositivo aplica-se diretamente aos procedimentos administrativos, mas sim que minimamente o $\S 1^{\circ}$ do art. 489, enquanto reforço da norma constitucional de que se está a tratar, deve nortear também a atuação do Poder Judiciário quando exerce atividade diversa daquela que é sua principal atividade.

Dessa forma, o dever de fundamentação/motivação deve ser aplicado a todas as decisões judiciais, por decorrer de norma constitucional. O artigo 489, $\S 1^{\circ}$, do CPC/2015 tentou evitar a falta de fundamentação para que não seja a decisão considerada nula, como preconiza o artigo 93, IX da CF/88 e também como trazido no artigo 1.022, parágrafo único, inciso II, do CPC/2015, que considera omissa a decisão que não observar o artigo 489, $\S 1^{\circ}$, do CPC/2015. (Leite; Streck; Nery Junior, 2017)

Ademais, Rodrigo Ramina de Lucca (2019, p. 225 - 226) menciona que:

[...] desenvolveu-se no Poder Judiciário brasileiro a concepção de que o juiz não precisa se manifestar a respeito de todas as alegações das partes; basta que apresente as razões de seu convencimento. Dito de outro modo, imagina-se que motivar uma decisão seja escolher argumentos que beneficiem a parte vencedora, pouco importando o que foi alegado e produzido pela parte vencida.

[...] uma má-compreensão da função da motivação das decisões judiciais e do significado de "questões relevantes ao processo". Há uma crença jurisprudencial generalizada de que é o juiz quem deve escolher quais alegações das partes são dignas de apreciação, filtrando aquilo que não considerar pertinente. Como consequência, a motivação acaba se tornando uma exaltação das razões que fundamentam o dispositivo, ignorando completamente tudo que foi produzido pela parte sucumbente. A decisão diz porque o vencedor venceu, mas não diz porque o sucumbente perdeu. [...] cada causa de pedir não analisada implica uma demanda não julgada.

Discute-se se a sentença sem fundamento não seria inexistente, em que pese a lei elencar como nula. Veja-se a

justificativa da doutrina para tal fundamento:

[...] na doutrina, afirma-se que é inexistente a sentença sem dispositivo, e que, havendo vários pedidos, a ausência de dispositivos a respeito de um deles impede que se considere que tal pedido tenha sido julgado (assim, Barbosa Moreira, Item do pedido sobre o qual não houve decisão, cit., p. 241 ss.). De modo similar, entendemos que poderá 
haver hipóteses em que a ausência de fundamentação poderá fazer com que se considere a decisão juridicamente inexistente, como se não tivesse sido proferida (Medina, 2020c, s. p.).

A ausência de fundamentação é motivo para anulação da sentença e não de reforma.

O dever deve ser observado também em se tratando de decisões interlocutórias, como por exemplo na decisão que determina a emenda a inicial, pois o defeito deverá ser indicado (Araújo, 2016). Apenas os despachos, que não têm conteúdo decisório, dispensam a fundamentação (Gonçalves, 2020).

Preocupa-se, na doutrina, sobre a possibilidade de opiniões pessoais do julgador interferirem na fundamentação. A respeito, escreve Neves (2016, s. p.):

[...] o art. 489 do Novo CPC não retira da decisão judicial sua característica de ato de criação solitário pelo magistrado. O juiz pode até estar mais controlado e sua atuação mais supervisionada pela lei, mas no final do dia é sempre o juiz, no isolamento de seu gabinete ou casa, quem profere a decisão. E é ali que ele faz interpretações a respeito do Direito que obviamente são influenciadas por suas opiniões pessoais. Afinal, adotar um dentre vários entendimento doutrinários plausíveis não é um ato humano que expressa uma opinião pessoal? Uma opinião pessoal fundada em argumentos sólidos, mas, ainda assim, uma opinião pessoal.

Apesar de influenciado por suas concepções pessoais, de forma indireta, não se pode admitir que o juiz utilize apenas dessas opiniões e crenças de forma direta para fundamentar suas decisões, sem nenhum tipo de embasamento no sistema jurídico. Semelhantemente, não pode ele amoldar a lei de forma que se encaixe em sua opinião pessoal, pois, assim agindo, estaria ele fugindo da sua real função.

Se o juiz se utilizar de forma indiscriminada da influência das suas concepções pessoais, como acima mencionado, acaba por seguir o ditame "o Direito é o que os tribunais dizem que é”, frase que inclusive já foi usada pela jurisprudência e doutrina, como por exemplo na Recl 4335/AC - STF (Streck, 2016).

Nesse sentido é o entendimento de Lenio Luiz Streck (2016, p. 67-68):

De minha parte, não concordo com a tese de que o direito é aquilo que o Judiciário diz que é. Fosse isso verdadeiro, não precisaríamos estudar nem escrever. O direito é um conceito interpretativo e é aquilo que é emanado pelas instituições jurídicas, sendo que as questões a ele relativas encontram, necessariamente, resposta nas leis, nos princípios constitucionais, nos regulamentos e nos precedentes que tenham DNA constitucional, e não na vontade individual do aplicador (e tampouco na vontade coletiva de um tribunal).

[...]Lia dia desses uma pesquisa feita no Judiciário do Paraná, onde um desembargador disse que não dá para esperar que o juiz se separe dos seus conceitos políticos, religiosos, etc. Fiquei pensando: como assim, Excelência? Quer dizer que a causa do cidadão depende do que o juiz pensa sobre o direito? Não me canso em repetir: a) juiz tem responsabilidade política; b) ele decide e não escolhe; c) a consciência do juiz não é um ponto cego ou isolado da cultura. Portanto, a frase do desembargador paranaense tem um problema: Ninguém nessa altura do campeonato acha que o juiz é uma alface ou que esteja amarrado aos textos como no iluminismo. Desde há muito tempo que a hermenêutica superou isso, na medida em que a carga de pré-conceitos não é um mal em si, mas uma aliada. Interpretar não é atribuir sentidos de forma arbitrária, mas é fazê-lo a partir do confronto com a tradição, que depende da suspensão dos pré-conceitos. Se o juiz não consegue fazer isso, não pode e não deve ser juiz. São os dois corpos do rei, como diria Kantorowicz. As decisões devem obedecer à integridade a à coerência do Direito.

O disposto no art. 489 do CPC aplica-se no âmbito do juizado especial, como determina o Enunciado 309 do Fórum Permanente de Processualistas Civis - FPPC.

Evidente que a tarefa de fundamentar é do magistrado e não pode ser transferida às partes, para que estas descubram o que "passou pela cabeça do magistrado" ao analisar determinado caso (Neves, 2016).

Vê-se a importância da fundamentação para o Estado Democrático de Direito, para as partes, bem como para toda sociedade, garantindo, assim, que não haja sentenças e decisões arbitrárias, mas que respeitem as garantias fundamentais elencadas na Constituição Federal. 


\subsection{Consequencialismo. Aspectos gerais}

Para Luis Fernando Schuartz (2008, p. 130-131), o consequencialismo jurídico é "qualquer programa teórico que se proponha a condicionar, ou qualquer atitude que condicione explícita ou implicitamente a adequação jurídica de uma determinada decisão judicante à valoração das consequências associadas a ela e às suas alternativas”.

Interessante a menção feita por Alexandre Pereira Dutra (2015, p. 01), que trouxe a lembrança de que o tema "consequencialismo" voltou a ter notoriedade depois de uma entrevista de Nelson Jobim, então ministro do Supremo Tribunal Federal, ao jornal Valor Econômico, em 2004:

Quando só há uma interpretação possível, acabou a história. Mas quando há um leque de interpretações, por exemplo, cinco, todas elas são justificáveis e são logicamente possíveis. Aí, deve haver outro critério para decidir. E esse outro critério é exatamente a consequência. Qual é a consequência, no meio social, da decisão A, B ou C? Você tem de avaliar, nesses casos muito pulverizados, as consequências. Você pode ter uma consequência no caso concreto eventualmente injusta, mas que no geral seja positiva. E é isso que eu chamo da responsabilidade do Judiciário das consequências de suas decisões.

O consequencialismo tem duplo conceito, ou, melhor dizendo, duas linhas de pensamento distintas, uma em sentido amplo e outra em sentido estrito, mas ambos mencionam a importância de considerar os resultados e também como eles acontecem.

O conceito amplo de consequencialismo envolve a defesa de uma análise não exclusiva dos resultados de uma ação. Isto é, uma ação poderia ser boa ou ruim, justa ou injusta, válida ou inválida, a depender também dos resultados que produz. No conceito estrito de consequencialismo, apenas as consequências deveriam ser relevantes para julgar uma determinada ação (Christopoulos, 2015).

Os atos praticados através do raciocínio consequencialista devem prever as consequências valiosas da ação. A fundamentação consequencialista possui dois modelos, sendo o primeiro conhecido como consequencialista puro e o segundo o modelo deontológico sensível a consequência (Dutra, 2015).

O consequencialismo puro é defendido por Richard Posner, sendo uma preocupação com as consequências, tanto as consequências do caso como as sistêmicas que fazem parte da decisão, como no exemplo do motorista que poderia ser multado por violar uma regra no caso de excesso de velocidade ou por agir de modo imprudente. Mas, as decisões baseadas em regras não seriam pragmáticas, em consequência "a escolha de uma regra em lugar de um padrão para governar determinada área do comportamento pode ser pragmática mesmo que alguns casos sejam decididos de modo falho para produzir as melhores consequências no particular" (Dutra, 2015).

O juiz, além de aplicar uma regra, visa a realidade social, mas Richard Posner fundamentava que o pragmatismo não é uma forma de consequencialismo, apesar de um juiz pragmático buscar elencar as boas consequências. O problema do consequencialismo puro é não apresentar critérios para valorar as consequências relevantes, ao não estabelecer limites colocando em perigo o Estado de Direito (Dutra, 2015).

Por outro lado, no modelo deontológico sensível, as consequências permitem que fatos incidam nas normas jurídicas, demonstrando preocupação com os resultados, mas sem abrir espaço para rompimento entre o direito e a expectativa. Assim, as consequências podem ser valoradas para a necessária ponderação (Dutra, 2015).

Todos que recorrem ao judiciário buscam a solução de seus conflitos. O magistrado deverá dar uma solução plausível, e que, conforme se verá, o consequencialismo estará presente nesta decisão, in verbis:

É preciso uma justificação de segunda ordem, nesses casos, para controlar as escolhas que foram feitas na eleição das premissas utilizadas na decisão, motivo por que é necessária uma argumentação pautada na consistência, coerência 
(normativa e fática) e consequências da decisão judicial. Enquanto a argumentação, com base na consistência e na coerência, busca justificar a decisão com aquilo que "faz sentido no sistema", a argumentação consequencialista pretende justificar a decisão com aquilo "faz sentido no mundo". Quanto a esse ponto, MacCormick ressalva a importância de o intérprete conhecer suas pré-compreensões para uma melhora compreensão do problema e escolha das premissas (Pereira, 2019, s. p).

Percebe-se que o consequencialismo é importante para adequar a norma à atual sociedade, elencando os efeitos positivos e negativos da decisão, todavia, o julgador não poderá fazer uso de suas convicções pessoais para decidir o que é melhor para a coletividade.

\subsection{Consequencialismo no direito brasileiro}

A Lei de Introdução às Normas do Direito Brasileiro (Dec.-Lei 4.657/1942) sofreu alterações através da Lei 13.655/2018, que incluiu diversos artigos. Dentre eles, destaca-se o art. 20, que elenca: "Nas esferas administrativa, controladora e judicial, não se decidirá com base em valores jurídicos abstratos sem que sejam consideradas as consequências práticas da decisão", ou seja, o magistrado deverá considerar as consequências práticas.

Em complemento, o art. 21 reza que "a decisão que, nas esferas administrativa, controladora ou judicial, decretar a invalidação de ato, contrato, ajuste, processo ou norma administrativa deverá indicar de modo expresso suas consequências jurídicas e administrativas".

Como mencionam Fausto Santos de Morais e Lucas Zolet (2018, p. 510):

Ao propor a consideração das consequências práticas de uma decisão judicial, a nova redação da LINDB avança em espaço controverso da Teoria do Direito contemporânea, qual seja da possibilidade das decisões judiciais se utilizarem de argumentação consequencialista sem decorrer em mero ativismo judicial.

Em tempos de controvérsia da interpretação e aplicação das normas jurídicas, questiona-se também qual deve ser a metodologia adotada para responder adequadamente aos dilemas que surgem em meio à crise de efetividade do Estado. Essa é uma questão que está a procura por respostas, especialmente, considerando a crítica de que o próprio Supremo Tribunal Federal não se preocupa com uma justificação rigorosa diante da utilização de valores abstratos no âmbito da argumentação jurídica.

Ainda, o Código de Ética da Magistratura Nacional aprovado na 68 a Sessão Ordinária do Conselho Nacional de Justiça, em agosto de 2008, menciona sobre o consequencialismo, conforme consta no art. 25 "especialmente ao proferir decisões, incumbe ao magistrado atuar de forma cautelosa, atento às consequências que pode provocar" (CNJ, 2008).

Afirma-se, ao tecer comentários sobre o consequencialismo na decisão judicial, sobre o perigo de elas impactarem negativamente a estrutura administrativa. Por exemplo, na hipótese de o magistrado conceder judicialmente medicamentos a determinada pessoa sob a ótica da dignidade da pessoa humana, poderia colocar em risco a saúde e a vida de outras pessoas. Assim, assim, nota-se, na doutrina, que:

a redação utilizada não deixa de ser problemática do ponto de vista da hermenêutica, pois se diz que, em diversas esferas (administrativa, controladora e judicial), não se decidirá com base em valores jurídicos abstratos sem que sejam consideradas as consequências práticas da decisão. A problemática reside no fato de que, do ponto de vista mais rigoroso da hermenêutica, a decisão será sempre concreta. Assim, sempre que se decide com base em um valor, a aplicação interpretativa se dá sobre o valor concreto e não há aplicação de valor abstrato, ainda que não se motive a decisão de forma concretizada (Motta; Nohara, 2019, s. p.).

Diante disso, o consequencialismo possibilitaria ao magistrado, em algumas situações, como no caso de lacuna, ao fundamentar a sua decisão, verificar se prevalece o interesse da sociedade, deixando de lado o direito individual da parte que busca no judiciário a solução de um litígio. 
Com a modificação da LINDB, surge a possibilidade de tomada de decisões por meio da consideração das suas consequências práticas. No entanto, não se sabe se "o volume necessário ou suficiente de considerações a serem levadas em conta pelos julgadores no âmbito de suas decisões", mas espera-se que o consequencialismo não seja utilizado para camuflar a arbitrariedade na tomada de decisões (Morais; Zolet; 2018, p. 518).

Segundo Schuartz (2008), há três tipos de consequencialismo jurídico “à brasileira", quais sejam: festivo, militante e o malandro. O consequencialismo festivo possui várias características, mas a principal é o desdém e o desprezo no que tange a solução de problemas por operadores do direito. Este tipo de consequencialismo possibilita uma ampla distinção entre a aplicação do direito e a formulação de políticas públicas. Há dois atributos: a crítica e desdenhosa da prática dos juristas e a superficialidade na escolha dos insumos teóricos. A importância do consequencialismo festivo aparece como papel corretivo, em relação ao segundo consequencialismo, o militante, que verá a seguir.

O consequencialismo militante surge por não seguir normas do direito e nem ao menos se preocupa em restruturar as referências normativas. Surge da reverência articulada do discurso sobre o respeito a tradição e os problemas do momento. Quem usa esse tipo de argumento não tem como provar seu acerto, mas também não tem como provar que está errado, já que quem faz uso do consequencialismo militar é uma autoridade que age com parcialidade e arbitrariedade, o que evidencia o risco, mas que o consequencialismo festivo tentar amenizar, pois o festivo utiliza métodos cientificamente "credenciados" (Schuartz, 2008).

Por fim, o último consequencialismo "à brasileira", o consequencialismo malandro, é uma estratégia argumentativa que utiliza da dogmática jurídica com o fim de ocorrer em desordem, apenas para apresentar uma proposta para a ordem. Deste modo, é um meio inválido. Entretanto, há pontos positivos, pois é necessário um vasto conhecimento. Produz inovações ao direito ao solucionar problemas específicos, reflete em exigências da isonomia, logo, esse tipo de consequencialismo demonstra que serve para o bem e para o mal e esse risco é desprezível (Schuartz, 2008).

Para Medina (2020a) algumas decisões admitem argumentos consequencialistas como fundamentação, mas esses argumentos não podem ser os únicos elementos para tomada de decisões. Os administradores devem observar a lei, para alcançar o melhor resultado, pois as consequências da decisão justificará o caminho a ser seguido, com base no melhor destino para a coletividade. Os juízes analisam as consequências das decisões mas de um modo diferente, como no caso do processo de execução, pois deverá analisar o modo menos gravoso para as partes, devendo seguir os princípios de ordem jurídica e não política. A decisão judicial busca resultado que produzirá efeito na sociedade. Desse modo, as consequências sempre estarão presentes; entretanto, a decisão não pode ter como único fundamento aquilo que o magistrado acredite ser o melhor para a sociedade, devendo buscar o melhor resultado jurídico para a lide.

Há decisões judiciais que tratam das consequências, mencionando o art. 20 LINDB, sendo que essas decisões ocorrem principalmente em demandas que envolvem a saúde humana. É notório que o direito à vida é o bem jurídico mais importante. Todavia, o judiciário, ao obrigar a administração a comprar o medicamento, poderia colocar em risco todo o sistema de saúde. Com esse pensamento sobre as consequências, o Tribunal de Justiça de Minas Gerais negou o pedido para obrigar o Sistema Único de Saúde a fornecer medicamento, veja-se:

[...] 3. A incorporação, a exclusão ou a alteração pelo SUS de novos medicamentos, produtos e procedimentos, bem como a constituição ou a alteração de protocolo clínico ou de diretriz terapêutica, são atribuições do Ministério da Saúde, assessorado pela Comissão Nacional de Incorporação de Tecnologias no SUS (Lei 8.080/90, art. 19-Q). 4. Tendo, a Conitec, avaliado as evidências científicas sobre eficácia, segurança, custo-efetividade e impacto orçamentário do medicamento esilato de nintedanibe para o tratamento de fibrose pulmonar idiopática, e concluído por sua não incorporação para dispensação na rede pública, não pode o Poder Judiciário substituir-se ao administrador, sem qualquer fundamento ou indicação de ilegalidade perpetrada, e determinar o seu fornecimento. 5. Cabe ao julgador, para inobservar a política pública adotada, justificar a sua decisão em eventual falha praticada pelo órgão administrativo competente, e, o que se faz também essencial: considerar os parâmetros e limites definidos pela 
LINDB - Lei de Introdução às Normas do Direito Brasileiro, notadamente as disposições contidas em seus artigos 20 a 24, que se referem à necessidade de avaliação das consequências práticas da decisão, e aos critérios a serem observados quando do controle da atuação administrativa. 6. "A gestão do Sistema Único de Saúde, obrigado a observar o princípio constitucional do acesso universal e igualitário às ações e prestações de saúde, só torna-se viável mediante a elaboração de políticas públicas que repartam os recursos (naturalmente escassos) da forma mais eficiente possível". "Obrigar a rede pública a financiar toda e qualquer ação e prestação de saúde existente geraria grave lesão à ordem administrativa e levaria ao comprometimento do SUS, de modo a prejudicar ainda mais o atendimento médico da parcela da população mais necessitada". (STA n. 175/CE, voto Min. Gilmar Mendes) 7. Não se pode aceitar que um relatório de médico particular, única prova técnica a instruir a petição inicial, possa sobrepujar as conclusões do órgão técnico, que detém a legitimidade e competência para estabelecer as políticas públicas para a área da saúde. 8. Recurso provido, para revogar a tutela antecipada de urgência concedida em primeiro grau, mantendo, no entanto, o agravante no polo passivo da lide. (TJMG - Agravo de Instrumento-Cv 1.0000.20.019572-5/001, Relator(a): Des.(a) Wander Marotta, $5^{\mathrm{a}}$ CÂMARA CÍVEL, julgamento em 30/07/2020, publicação da súmula em 03/08/2020) (Brasil, 2020).

A título de ilustração, também o Tribunal de Justiça do Paraná, decidiu com base no art. 20, da LINDB, ou seja, com análise da consequência da decisão, desta vez, referente a obrigação financeira, in verbis:

AGRAVO DE INSTRUMENTO. EXECUÇÃO DE TÍTULO EXTRAJUDICIAL. DECISÃO QUE RECONHECE A POSSIBILIDADE IN ABSTRACTO DA PENHORA DE PARCELA DO BENEFÍCIO PREVIDENCIÁRIO DO DEVEDOR, MAS INDEFERE A MEDIDA EM RAZÃO DA EXISTÊNCIA DE EMPRÉSTIMOS CONSIGNADOS, COMO FORMA DE PROTEÇÃO AO MÍNIMO EXISTENCIAL. INDEFERIMENTO DO PLEITO DE RESERVA DE FUTURA MARGEM CONSIGNÁVEL, POR MEIO DA PROIBIÇÃO À CONTRATAÇÃO DE NOVOS EMPRÉSTIMOS. IMPOSSIBILIDADE DA MEDIDA. PATRIMÔNIO DO DEVEDOR QUE RESPONDE PELAS OBRIGAÇÕES CONTRAÍDAS (CPC, ART. 789). SANÇÃO EXECUTIVA QUE NÃO PODE RECAIR SOBRE A PESSOA DO DEVEDOR, LIMITANDO SUA CAPACIDADE PARA CONTRAIR DIREITOS E OBRIGAÇÕES. EXAME DAS CONSEQUÊNCIAS DA DECISÃO (LINDB, ART. 20,). DECISÃO MANTIDA. RECURSO CONHECIDO E DESPROVIDO. CAPUT. Alvo expressa autorização legal, o cumprimento das obrigações pecuniárias ativa a responsabilidade patrimonial do devedor, de modo que a sanção executiva não pode impedi-lo de praticar os atos da vida civil, como a contratação de novos empréstimos consignados. - Recurso conhecido e desprovido. (TJPR - 13a C.Cível - 0052659-04.2019.8.16.0000 - Londrina - Rel.: JUIZ DE DIREITO SUBSTITUTO EM SEGUNDO GRAU RODRIGO FERNANDES LIMA DALLEDONE - J. 23.03.2020) (Brasil, 2020).

Percebe-se que o Poder Judiciário recorre à análise das consequências que as decisões produzirão, e que, muitas vezes, trata-se de situação de extrema dificuldade, como no caso do primeiro julgado citado, considerando que poderá obrigar a Administração Pública a fornecer o medicamento, e por consequência, deixará outras pessoas desamparadas pelo órgão, porém, o indeferimento, poderá levar a morte de uma pessoa, o que também possui consequências, pois o Estado tem a obrigação efetivá-lo, sendo um direito do cidadão e um dever do Estado como bem elenca a Constituição.

Por fim, mister se faz mencionar que o direito brasileiro não aceita o consequencialismo puro. De acordo com a Constituição Federal ele poderá integrar o suporte fático, mas o magistrado não poderá decidir apenas com base nas consequências, ou seja, apenas servirá de parâmetro, como no caso de confronto de direitos fundamentais (Medina, 2020a).

\section{Conclusão}

Conforme narrado, é obrigatório que o magistrado fundamente toda sentença ou decisão, portanto, deverá ocorrer a ligação dos fatos com o dispositivo, demonstrando o motivo do resultado e não somente mostrando quais aparatos legais foram utilizados. Dessa forma, o Poder Judiciário assegura ao jurisdicionado outras garantias constitucionais, como a ampla defesa, o contraditório e a imparcialidade.

Diante disso, é preciso que o julgador separe as suas convicções políticas e religiosas quando for proferir uma decisão, não sendo admissível que utilize meios incertos para o caso concreto, ou que não enfrente todos os argumentos, ou que apenas mencione os dispositivos - essas são inclusive, algumas das vedações elencadas no Código de Processo Civil de 2015. 
Em recentes mudanças a Lei de Introdução as Normas do Direito Brasileiro, menciona-se que as decisões deverão ser proferidas levando em consideração as suas consequências. Assim, deve-se ter em mente o consequencialismo puro e o deontológico sensível. O primeiro é vedado no direito brasileiro, já que o magistrado não poderá analisar apenas a consequências para julgar; já o segundo tem uma preocupação com os resultados, ou seja, almeja o equilíbrio.

O mundo está sofrendo com o novo coronavírus (COVID-19). A Organização Mundial da Saúde - OMS, em março de 2020 declarou que elevou o estado da contaminação à pandemia. Trata-se de uma doença contagiosa, que coloca em risco principalmente os idosos e as pessoas com doenças crônicas. Até o momento, pela pouca quantidade de vacinas ou pela ausência de remédio para tratamento, o meio mais eficaz para coibir a transmissão é o isolamento e distanciamento social.

No atual cenário em que se encontra a sociedade brasileira, com os problemas políticos gerados face a doença que assola o mundo, com orientação dos especialistas em saúde sobre manter o isolamento, fechamento de fronteiras e comércio pensando nos mais vulneráveis -, do outro lado, pessoas e políticos mais preocupados com a economia e com empregos, deixam a sociedade sem saber qual caminho seguir.

Diante desse confronto para ver "quem está com a razão" e qual medida deveria ser tomada, resta ao judiciário decidir, motivar e fundamentar suas decisões, trazendo manifestações coerentes, justas, céleres e que contribuam para o bemestar social e saúde coletiva.

Questões relacionadas à pandemia com frequência chegam ao Judiciário para decidir qual rumo seguir, e tais decisões estão tendo em sua maioria, fundamentos consequencialistas, visando alcançar o "melhor resultado para a sociedade", e analisando as consequências que aquela decisão gerará à toda a coletividade. Como exemplo dessas decisões, cita-se o caso que ocorreu no município de Volta Redonda-RJ, oportunidade em que o magistrado desta cidade acolheu os fundamentos do Ministério Público e determinou que o município editasse decreto mais rígido, para assim, restringir as atividades que não era considerada como essenciais, tendo em vista, que naquele período (abri1/2021) já havia ocupação de $50 \%$ dos leitos para UTI (autos $\mathrm{n}^{\circ}$. 0006109-26.2020.8.19-0066).

Sob um prisma consequencialista, se poderia afirmar que esse melhor resultado, ou melhores consequências, seriam justamente medidas que afrouxam o distanciamento social, afinal de contas se verificar todos os pontos que podem prejudicar a sociedade, o distanciamento e o isolamento não são benéficos para e economia. Então, na visão consequencialista, não haveria como sacrificar somente a economia e proteger a saúde, porque não estariam sendo observadas as consequências.

Mas, afinal, é melhor aplicar o consequencialismo, ou não?

$\mathrm{O}$ consequencialismo desmedido deve ser repudiado, até porque geralmente embasado em questões políticas e econômicas. No entanto, o consequencialismo pode ser usado somente como meio de "ponderação", nos termos a que antes nos referimos.

Decisões motivadas e fundamentadas corretamente vão, por consequência, trazer o melhor para toda a sociedade e, inclusive, garantirão a observância dos princípios constitucionais e trarão maior segurança jurídica para os jurisdicionados que, só assim, estarão devidamente "protegidos pela lei e pelo judiciário", fazendo jus a denominação de Estado Democrático de Direito.

\section{Referências}

Alvim, A. (2020). Manual de Direito Processual Civil [livro eletrônico]. (4a ed). Thomson Reuters Brasil.

Alvim, T. A. (2019). CPC em foco temas essenciais e sua receptividade [livro eletrônico]. (2a ed). Thomson Reuters Brasil.

Araújo, F. C. de. (2016). Curso de processo civil: parte geral. Malheiros.

Brasil. (2015). Lei $n^{o}$. 13.105, de 16 de março de 2015: Código de processo civil. Brasília, DF.

Brasil. (2020). Tribunal de Justiça do Estado de Minas Gerais. Autos nº 1.0000.20.019572-5/001, Relator: Wander Marotta, Minas Gerais. 
Brasil (2020). Tribunal de Justiça do Estado do Paraná. Autos nº. 0052659-04.2019.8.16.0000. Relator Rodrigo Fernandes Lima Dalledone. Paraná.

Christopoulos, B. G. C. (2015). Argumentos consequencialista no direito. Revista Eletrônica do Mestrado em Direito da UFAL. 6(3), 4 - 27. https://www.seer.ufal.br/index.php/rmdufal/article/view/2061.

CNJ (2008). Código de ética da magistratura nacional. Conselho Nacional de Justiça. https://www.cnj.jus.br/wpcontent/uploads/2011/01/codigo_de_etica_da_magistratura_nacional.pdf.

Dutra, A. P. (2015). Argumentação consequencialista no direito: modelo teórico e exemplos de aplicação. Revista de Doutrina da $4^{a}$ Região, https://revistadoutrina.trf4.jus.br/index.htm?https://revistadoutrina.trf4.jus.br/artigos/edicao064/Alexandre_Dutra.html.

Francesconi, T. R. H. (2019). O dever de fundamentação das decisões judiciais. Orientador: Olavo de Oliveira Neto. 2019. Dissertação (Mestrado em Direito). Pontifícia Universidade Católica. https://tede2.pucsp.br/handle/handle/22157.

Gonçalves, M. V. R., \& Lenza, P. (coord.). (2020). Direito processual civil esquematizado [livro eletrônico]. (11a ed). Saraiva.

Leite, G. S. Streck, L. L., \& Nery Junior, N. (coord.) (2017). Crise dos Poderes da República: judiciário, legislativo e executivo. Editora Revista dos Tribunais. Lucca, Rodrigo Ramina de (2019). O dever de motivação das decisões judiciais: estado de direito, segurança jurídica e teoria dos precedentes. (3a ed). JusPodivm.

Marinoni, L. G., Arenhart, S. C. \& Mitidiero, D. (2020). Código de processo civil comentado [livro eletrônico]. (6a ed). Thomson Reuters Brasil.

Medina, J. M. G. (2020a). Curso de direito processual civil [livro eletrônico]. (5a ed). Thomson Reuters Brasil.

Medina, J. M. G. (2020b). Constituição Federal comentada [livro eletrônico]. (3a ed). Thomson Reuters Brasil.

Medina, J. M. G. (2020c). Código de processo civil comentado [livro eletrônico]. (4a ed). Thomson Reuters Brasil.

Medina, J. M. G., \& Fonseca, J. P. da. (2019). Fundamentação da decisão judicial no código de processo civil. Revista Relações Internacionais do Mundo Atual. 4 (25). http://revista.unicuritiba.edu.br/index.php/RIMA/article/view/3957.

Mezzaroba, O., \& Monteiro, C. S. (2009). Manual de metodologia da pesquisa no direito. (5a ed.) Saraiva.

Mitidiero, D. (2019). Colaboração no processo civil [livro eletrônico]. (2a ed). Thomson Reuters Brasil.

Morais, F. S. de, \& Zolet, L. (2018). A Nova Lindb e os Problemas da Argumentação Consequencialista. Revista Juridica, $3(52), 497$ - 523. http://revista.unicuritiba.edu.br/index.php/RevJur/article/view/3229.

Motta, F., \& Nohara, I. P. (2019). LINDB no direito público [livro eletrônico]. Thomson Reuters Brasil.

Nery Júnior, N., \& Nery, R. M. de A. (2019). Código de Processo Civil Comentado [livro eletrônico]. (4a ed.), Thomson Reuters Brasil.

Neves, D. A. A. (2016). Manual de direito processual civil [livro eletrônico]. (8a ed). JusPodivm.

Pereira, C. F. B. (2019). Fundamentação das decisões judiciais: o controle da interpretação dos fatos [livro eletrônico]. Thomson Reuters.

Schuartz, L. F. (2008). Consequencialismo jurídico, racionalidade decisória e malandragem. Revista de Direito Administrativo FGV. 248. $<$ http://bibliotecadigital.fgv.br/ojs/index.php/rda/article/view/41531.

Streck, L. L., \& Raatz, I. (2017). O dever de fundamentação das decisões judiciais sob o olhar da crítica hermenêutica do direito. R. opin. Jur., (20), 160-179. https://periodicos.unichristus.edu.br/opiniaojuridica/article/view/1400.

Streck, L. L. (2016). Juiz não é Deus: juge n' est pas Dieu. Juruá.

Silva, D. P. e. (2012). Vocabulário jurídico conciso. (3a ed). Forense. 